\title{
Organic solvent extraction of uranium from alkaline nuclear waste
}

\author{
Manny Mathuthu ${ }^{1} \cdot$ Naomi D. Mokhine ${ }^{1} \cdot$ Elizabeth Stassen $^{2}$
}

Received: 25 June 2018 / Published online: 14 February 2019

(c) The Author(s) 2019

\begin{abstract}
There are proliferation issues with the Plutonium Uranium Redox Extraction process due to the possibility of recovering plutonium. The objective of this research was to evaluate different organic extraction ligands that can remove uranium from the nuclear waste and to determine the most effective organic solvent for extracting uranium only, from alkaline media. The results indicate that Alamine 336 in xylene has zero (0\%) extraction capability for surrogate fission products at an optimum extraction time of $15 \mathrm{~min}$. Aliquat 336 in xylene has an extraction percentage of $72 \%$ for uranium in 60 min. However, Aliquat 336 in toluene extracted $82 \%$ of the uranium from the feed solution after $30 \mathrm{~min}$, decreasing to $76 \%$ after $60 \mathrm{~min}$.
\end{abstract}

Keywords Aliquat $336 \cdot$ Alkaline media $\cdot$ Aqueous solution $\cdot$ Extraction ligand $\cdot$ Organic solvent

\section{Introduction}

A large amount of uranium in the environment is caused by human activities such as mining and milling of other minerals and also from operations of reactors, reprocessing of spent nuclear fuel (SNF) and its disposal [1,2]. It is also of great commercial interest due to its application in the nuclear industry especially in the use and development of new radiopharmaceuticals and radioisotopes [3].

The uranium waste contains insoluble precipitates formed when the target plates uranium-aluminum alloy are dissolved during the production of Mo-99 [4]. The remaining insoluble residue contains about $90 \%$ of enriched uranium that is present in the mixture of various oxidation states.

A process of ammonium carbonate-based dissolution has been developed for uranium recovery from the waste generated by an alkaline dissolution process used for the production of the medical isotope Mo-99 [5]. Uranium recovery from residue was achieved with three successive ammonium

Manny Mathuthu

Manny.Mathuthu@nwu.ac.za

Naomi D. Mokhine

dikeledi.mokhine@gmail.com

1 Center for Applied Radiation Science and Technology (CARST), North-West University (Mafikeng), Mmabatho 2735, South Africa

2 South African Nuclear Energy Cooperation SOC Ltd (NECSA), Pelindaba, South Africa carbonate-peroxide leaches with final decontamination factors from low values of 1-10 Cs-137, Ru-106, and Sb-125 to infinity.

The most commonly used processes for purification and concentration are ion exchange and solvent extraction. Solvent extraction (SX) is one used to recover and separate uranium from sulphuric acid leach liquors [6]. The most well-known process worldwide for extraction of uranium from spent nuclear fuel is the Plutonium Uranium Redox Extraction (PUREX) process, where nitric acid solution is used with Tributyl phosphate (TBP) as an extractant. Smith et al. [7] have studied the dissolution of $\mathrm{UO}_{2}, \mathrm{U}_{3} \mathrm{O}_{8}$ and $\mathrm{UO}_{3}$ in carbonate solution with the counter cations $\mathrm{NH}^{+}, \mathrm{Na}^{+}, \mathrm{K}^{+}$ and $\mathrm{Rb}^{+}$. In a solution of $1.0 \mathrm{M}$ carbonate and $0.1 \mathrm{M} \mathrm{H}_{2} \mathrm{O}_{2}$, it was found that the most rapid dissolution occurs in ammonium carbonate. The authors also compared the dissolution rates of the different uranium oxides and found the rate to be decreasing from $\mathrm{UO}_{3}>>\mathrm{U}_{3} \mathrm{O}_{8}>\mathrm{UO}_{2}$. This is expected since the oxidation state of uranium required to be +6 after dissolution.

Kim et al. [8] investigated solvent extraction of uranium using amine based extractants. Amine based extractants such as, Alamine 336, Alamine 308, Alamine 304 and Aliquat 336 in diluent kerosene were investigated. The results showed that Alamine 336 was the best extractant for uranium from sulphate solutions compared to other amine extractants. Extraction percentage of $99.8 \%$ was recovered from low grade ore without interference of other metals. 
Zhu et al. [9] stated in his study of solvent extraction of uranium and separation of vanadium that quaternary amine could be used to extract uranium from alkaline solution, but its application is prevented by the formation of a third phase. The results were reported that more than $98 \%$ of uranium was extracted using 3\% (w/v) of Aliquat 336 and 3\% (w/v) isodecanol in Shellsol D70 from carbonate leach solution. The authors reported that over $90 \%$ of uranium was stripped from loaded organic solution. Stepanov et al. [10] studied a new technology that can be used for reprocessing of spent nuclear fuel, the so called CARBEX (carbonate extraction) process. The same workers reported that CARBEX process can be more effective and safe than PUREX process. Fourie et al. [11] stated that the recovery of uranium from Mo-99 production waste will reduce the residue volumes that need to be disposed of, while the recuperated enriched uranium can be used during the production of this isotope. This would decrease the cost of production.

The uranium waste consists of an insoluble precipitate formed when the target plates containing uranium-aluminum alloy are dissolved during the production of Mo-99 [4]. This solid residue contains uranium and most fission products, like molybdenum (Mo-99), cesium (Cs-137), strontium (Sr-90), barium (Ba-140), antimony (Sb-125), tellurium (Te-132), iodine (I-131) and a portion of the ruthenium (Ru-106) and zirconium (Zr-95).

$\mathrm{U}$ is an element that presents various oxidation states $\left(\mathrm{U}^{2+}, \mathrm{U}^{3+}, \mathrm{U}^{4+}, \mathrm{U}^{5+}\right.$ and $\left.\mathrm{U}^{6+}\right)$, of which uranous $\left(\mathrm{U}^{4+}\right)$ and uranyl $\left(\mathrm{U}^{6+}\right)$ are the most important [3]. A dissolution study for the recovery of uranium waste produced from Mo-99 was first conducted at Kernforschungszentrum Karlsruhe (KFK) [12]. This work was concentrated on using carbonate/bicarbonate mixtures as the dissolution medium with different oxidizing reagents e.g. hydrogen peroxide. Stepanov et al. [10] stated that carbonate solutions differ from acid leach solutions because they do not show oxidative activity when there are no oxidants. Therefore, oxidants are needed for an effective dissolution of uranium dioxide in carbonate solution. Most researchers use hydrogen peroxide as an oxidant to convert $\mathrm{U}(\mathrm{IV})$ to $\mathrm{U}(\mathrm{VI})$. Uranyl ion $\mathrm{UO}_{2}{ }^{2+}$ forms strong complexes with different carbonates and natural organic matter ligands depending on the $\mathrm{pH}$ [1].

When extracting uranium, whether through acid or alkaline leaching, it must be oxidized to the hexavalent state U(VI), before it is dissolved [13]. An advantage of using alkaline leaching is high selectivity of uranium over impurities because some of the impurities do not dissolve in alkaline solution [9]. Furthermore, it causes no corrosive activity in the equipment and carbonates are nontoxic to biological objects. The formation of uranyl carbonate-peroxide complex ions has been observed in sodium carbonate and hydrogen peroxide medium. It was proven in the alkaline leaching, that hydrogen peroxide plays two roles, firstly as an oxidant that accelerates the rate of dissolution, and secondly as a strong ligand forming mixed carbonate-peroxide complex when reacting with uranium [14].

The use of anodic dissolution of simulated spent nuclear fuel containing $\mathrm{UO}_{2}$ and fission products in alkaline aqueous solution using sodium carbonate-sodium bicarbonate [15] and ammonium carbonate solutions [16] has been performed. In these studies, uranyl ions were produced anodically as stable carbonate complexes, and at the same time, simulated fission products were precipitated as hydroxo or carbonate compounds. Uranyl ions were recovered as hydroxo compounds by adding sodium hydroxide to the solution after removing the Fission products precipitates. During the dissolution experiments, precipitates of the simulated fission products were observed on the pellet and in $\left(\mathrm{NH}_{4}\right)_{2} \mathrm{CO}_{3}$ solution used as the electrolytic solution. Analysis of the electrolytic solution revealed that most of the simulated fission products, i.e. alkaline earth and rare earth elements, are precipitated in high ratios [16]. The aim of this work was to investigate the extraction of Uranium from irradiated target waste residue plates for Mo-99 production using alkaline extraction technology. This is therefore a new application of an existing process. In alkaline leaching, oxygen is used as a strong oxidizing agent. However, in alkaline leaching, ammonium carbonate is used instead of sodium carbonate because reagents are recoverable for re-use, ammonium carbonate is a milder alkali than sodium carbonate leading to reduced chance of uranium precipitation. Uranium oxidizes and forms carbonate-peroxide complexes when uranium dioxide is oxidatively dissolved in carbonate solution containing hydrogen peroxide, which eventually converts to the soluble uranyl carbonate anion $\mathrm{UO}_{2}\left(\mathrm{CO}_{3}\right)_{3}^{4-}[17]$. Equation 1 shows the main reaction that take place:

$\mathrm{UO}_{2}+\mathrm{H}_{2} \mathrm{O}_{2}+3\left(\mathrm{NH}_{4}\right)_{2} \mathrm{CO}_{3}=\left(\mathrm{NH}_{4}\right)_{4} \mathrm{UO}_{2}\left(\mathrm{CO}_{3}\right)_{3}+2 \mathrm{NH}_{4} \mathrm{OH}$.

\section{Theory}

The percentage amount of uranium extracted during the extraction process can be calculated using the following equations:

$D=\frac{[U i]-[U f]}{[U f]}$,

where $\mathrm{D}$ is distribution ratio, $\mathrm{U}_{\mathrm{i}}$ is initial concentration before extraction and $U_{\mathrm{f}}$ is final concentration after extraction

$\% E=\frac{100 D}{D+\frac{V_{a q}}{V_{\text {org }}}}$,

where $\% \mathrm{E}$ is the extraction percentage, $\mathrm{V}_{\mathrm{aq}}$ is the volume of the aqueous phase and $\mathrm{V}_{\text {org }}$ is the volume of the organic phase. 


\section{Experimental}

\section{Phase 1: Evaluation of the organic solvent using surrogates}

\section{Sample preparation}

A total of 90 samples of organic solvents were prepared using three different extractants (Alamine 336 and Aliquat 336) and three different diluents (kerosene (viscosity, 1.30 at $40{ }^{\circ} \mathrm{C}$ and dielectric constant of 1.8 at $20^{\circ} \mathrm{C}$ ), Xylene (viscosity of 0.81 and dielectric constant of 2.57 at $20^{\circ} \mathrm{C}$ ), and benzene (viscosity: $0.6520^{\circ} \mathrm{C}$ and dielectric constant: 2.3 at $20^{\circ} \mathrm{C}$ ) at varying extraction time. A measure of $30 \mathrm{ml}$ of each of the extractants; Aliquat 336 and Alamine 336 were mixed with $70 \mathrm{ml}$ of each of the diluents. A $2 \mathrm{M}$ solution of ammonium carbonate was prepared in $1000 \mathrm{ml}$ of deionized water. Surrogate impurities ( $\mathrm{Sr}, \mathrm{Sb}, \mathrm{Ce}, \mathrm{Fe}, \mathrm{Nd}$, and $\mathrm{Mg}$ ) were dissolved in the ammonium carbonate solution.

\section{Extraction procedure}

$20 \mathrm{ml}$ of surrogate solution and $20 \mathrm{ml}$ of each organic solution were added together in falcon tubes and rotated using a Stuart SB3 (Bibby Scientific, United States) rotator for varying times from 3 to $30 \mathrm{~min}$. The solution was then transferred into a separatory funnel and was left for an hour to allow the aqueous and organic phases to separate. The organic phase was eluted and the aqueous phase was analyzed by Inductively Coupled Plasma Mass Spectroscopy (ICP-MS). This procedure was repeated for each organic solution.

\section{Aqueous sample for ICP-MS analysis}

$5 \mathrm{~g}$ of aqueous sample was weighed in a crucible. $5 \mathrm{ml}$ of $65 \%$ nitric acid and $1 \mathrm{ml}$ of $32 \%$ hydrochloric acid were added to the sample. The samples were placed in an Anton Par 3000 Microwave digester and left overnight to digest. An aliquot of $5 \mathrm{ml}$ from each sample was diluted to $100 \mathrm{ml}$ using deionized water and analyzed using a calibrated Agilent 7500 CE ICP-MS. Each sample was analyzed in duplicates.

\section{Phase 2: Evaluation of best diluent using uranium samples}

\section{Sample preparation}

The uranyl solution used for the extraction was generated from the dissolution of Uranium Ore Concentrate (UOC) with ammonium carbonate and hydrogen peroxide solution. A $0.01 \mathrm{M}$ solution of uranium in $1 \mathrm{M}$ of ammonium carbonate was prepared by dissolving $0.70 \mathrm{~g}$ of $\mathrm{U}_{3} \mathrm{O}_{8}$ in $250 \mathrm{ml}$ of carbonate solution. $30 \%$ hydrogen peroxide was added as an oxidant to a final concentration of $0.9 \mathrm{M}$ in the mixture, which was heated for $60 \mathrm{~min}$ at $60^{\circ} \mathrm{C}$. After an hour, the reaction was complete, heating was stopped and the solution was cooled down. The solution was then filtered using a 541 Whatman filter paper. The filter paper was washed with a small amount of deionized water. The final volume of the solution was recorded.

\section{Pre-equilibrium}

During SX, there is a decrease in feedstock solution volumes and inaccurate concentration values after extraction due to the occurrence of co-extraction of the feed solution into the organic solution. To prevent this, the organic phase has to be pre-equilibrated with feed solution that does not contain any solute using the following steps. (1) An equal amount of aqueous feed phase without solute (without $\mathrm{U}$ ) and organic extractant phase was added in $50 \mathrm{ml}$ falcon tubes. (2) The falcon tubes were inserted in a rotator at $7 \mathrm{rpm}$ for $60 \mathrm{~min}$. (3) After $60 \mathrm{~min}$, the solutions in the tubes were transferred into a separatory funnel and left for an hour to allow the two phases to separate. (4) The pre-equilibrated organic phase was poured into a separate container for further use.

\section{Extraction procedure}

The $\mathrm{U}_{3} \mathrm{O}_{8}$ dissolved in $\left(\mathrm{NH}_{4}\right)_{2} \mathrm{CO}_{3}$ was used as the aqueous feedstock for the extraction step. Xylene, Kerosene and Toluene (viscosity: 0.59 at $20^{\circ} \mathrm{C}$ and dielectric constant: 2.4 at $25^{\circ} \mathrm{C}$ ) were used as organic phase extracting agents. The aqueous solution obtained from $\mathrm{U}_{3} \mathrm{O}_{8}$ dissolution and preequilibrated organic solution were added together in a falcon tube at a ratio of 1:1. Step 2-4 in pre-equilibration process was repeated. Following phase contact and reaching equilibrium in step 3, the solution was left for $60 \mathrm{~min}$ to ensure that mass transfer equilibrium is reached. The aqueous and organic phases were separated by separation funnel and the aqueous phase was used to prepare the solution used for UV VIS analysis. An aliquot of uranium from the aqueous solution was transferred into a $25 \mathrm{ml}$ volumetric flask. $3 \mathrm{ml}$ of sodium carbonate and $1 \mathrm{ml}$ of hydrogen peroxide was added to the flask and diluted with deionized water. Then the sample was analyzed at $450 \mathrm{~nm}$ using a CARY 100 VARIAN UV-VIS Spectrophotometer, after setting up of a calibration curve in the region 50-200 ppm. The extraction was performed for various time periods of 15, 30, 45 and $60 \mathrm{~min}$.

Figure 1 shows the experimental setup for the separation of aqueous phase and organic phase. After allowing the two phases to separate, the organic phase is eluted, and the aqueous phase is analyzed. During the extraction process, it was found that a third phase appeared when extraction of uranium using Aliquat 336 with kerosene was performed. 


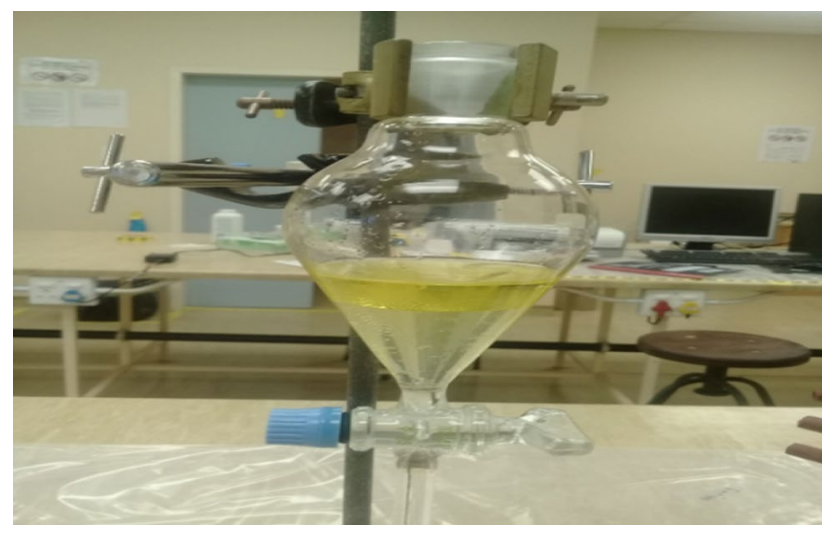

Fig. 1 Experimental setup for the separation of aqueous phase and organic phase

Due to the appearance of a third phase, the diluent kerosene was eliminated from the experiment

From the alkaline solution containing $2 \mathrm{M}$ of ammonium carbonate and 0.9 M hydrogen peroxide, the extraction of surrogates $\mathrm{Mg}$ and $\mathrm{Fe}$ (representative of activation products), and $\mathrm{Sr}, \mathrm{Sb}, \mathrm{Ce}, \mathrm{Nd}$ (representative of fission products) was carried out using Aliquat-336 and Alamine-336 as extracting agents dissolved in each of kerosene, xylene and benzene respectively.

\section{Evaluation of the best diluent}

Furthermore in this study, evaluation of the best diluent for optimal uranium extraction was investigated. From the alkaline solution containing $1 \mathrm{M}$ of ammonium carbonate and $0.9 \mathrm{M}$ of hydrogen peroxide, the extraction of uranium was carried out using Aliquat 336 which was dissolved in each of kerosene, xylene and toluene respectively.

\section{Results and discussion}

\section{Phase 1: Evaluation of the organic solvent using surrogates}

The evaluation of different extractants and diluents were investigated at different times. The experimental data of extraction of surrogates at various time $(3,10,15,20$ and $30 \mathrm{~min})$ using different organic solvents are reported in Tables 1, 2, 3, 4 and 5. These results show the best combination of extractants and diluents at various times. However, these studies were performed at $1 \mathrm{M}$ ammonium carbonate, which is not optimal for $\mathrm{U}$ extraction, and the influence of ammonium carbonate concentration on the extraction of the fission product surrogates were therefore investigated in the next section.

The negative extraction percentages indicate that precipitation has occurred. This is a positive indication that separation of uranium from these products may be possible by extracting uranium only using the organic extractants in prototype experiments. Table 6 shows that the optimum extraction time was found to be 15 min with Alamine 336 in Xylene.

Aliquat 336 in xylene, kerosene and toluene was selected for the extraction of uranium from alkaline solutions as it is a quaternary amine reagent shown to be a successful extractant from carbonate media by Stepanov et al. [10]. It is an ionic liquid reagent similar to Alamine 336. Aliquat 336 extracts metal ions higher than other extractants. The increase in metal extractions by Aliquat 336 is due to the increase in basic property of alkyl group which improves the cation-anion ion pair
Table 1 Extraction percentages for surrogates at 3 min rotating time

Table 2 Extraction percentages for surrogates at $10 \mathrm{~min}$ rotating time

\begin{tabular}{|c|c|c|c|c|c|c|}
\hline \multirow[t]{2}{*}{ Element } & \multicolumn{3}{|l|}{ Alamine 336} & \multicolumn{3}{|c|}{ Aliquat 336} \\
\hline & Kerosene & Xylene & Benzene & Kerosene & Xylene & Benzene \\
\hline $\mathrm{Mg}$ & -125.0 & -36.4 & -127.3 & -25.0 & -22.7 & -25.0 \\
\hline $\mathrm{Fe}$ & -95.4 & -20.7 & -129.9 & -20.7 & -14.9 & -60.9 \\
\hline $\mathrm{Sr}$ & $-1,049,900.0$ & $-354,900.0$ & $-550,180.0$ & -450.0 & -150.0 & -435.0 \\
\hline $\mathrm{Ce}$ & -80.8 & -7.7 & -23.1 & 29.6 & 30.4 & 18.8 \\
\hline $\mathrm{Nd}$ & -12.3 & 23.2 & 8.2 & 40.9 & 55.0 & 34.1 \\
\hline
\end{tabular}

\begin{tabular}{|c|c|c|c|c|c|c|}
\hline \multirow[t]{2}{*}{ Element } & \multicolumn{3}{|c|}{ Alamine 336} & \multicolumn{3}{|c|}{ Aliquat 336} \\
\hline & Kerosene & Xylene & Benzene & Kerosene & Xylene & Benzene \\
\hline $\mathrm{Mg}$ & -104.5 & -25.0 & -13.6 & -77.3 & -79.5 & -88.6 \\
\hline $\mathrm{Fe}$ & -83.9 & -10.9 & -60.9 & -78.2 & -66.7 & -106.9 \\
\hline $\mathrm{Sr}$ & $-33,900.0$ & $-544,900.0$ & -245.0 & -190.0 & -49.0 & -20.0 \\
\hline $\mathrm{Ce}$ & -69.2 & -7.7 & 19.2 & 11.5 & 7.7 & -7.7 \\
\hline $\mathrm{Nd}$ & -18.2 & 34.1 & 9.1 & 37.7 & 29.1 & 0.0 \\
\hline
\end{tabular}


Table 3 Extraction percentages for surrogates at $15 \mathrm{~min}$ rotating time

\begin{tabular}{|c|c|c|c|c|c|c|}
\hline \multirow[t]{2}{*}{ Element } & \multicolumn{3}{|l|}{ Alamine 336} & \multicolumn{3}{|l|}{ Aliquat 336} \\
\hline & Kerosene & Xylene & $\overline{\text { Benzene }}$ & Kerosene & Xylene & Benzene \\
\hline $\mathrm{Mg}$ & -104.5 & -68.2 & -27.3 & -140.9 & -40.9 & -31.8 \\
\hline $\mathrm{Fe}$ & -66.7 & 1.0 & -89.7 & -55.2 & -31.0 & -72.4 \\
\hline $\mathrm{Sr}$ & $-264,900.0$ & 0.0 & -525.0 & $-295,035.0$ & -270.0 & ND \\
\hline $\mathrm{Ce}$ & -53.8 & 0.0 & 9.6 & -3.8 & 28.8 & 11.5 \\
\hline $\mathrm{Nd}$ & 8.2 & 0.0 & 30.0 & 38.6 & 51.8 & -31.8 \\
\hline
\end{tabular}

Table 4 Extraction percentages for surrogates at $20 \mathrm{~min}$ rotating time

Table 5 Extraction percentages for surrogates at $30 \mathrm{~min}$ rotating time

Table 6 Effects of surrogate's extraction at the best various extractants

\begin{tabular}{|c|c|c|c|c|c|c|}
\hline \multirow[t]{2}{*}{ Element } & \multicolumn{3}{|l|}{ Alamine 336} & \multicolumn{3}{|l|}{ Aliquat 336} \\
\hline & Kerosene & Xylene & Benzene & Kerosene & Xylene & Benzene \\
\hline $\mathrm{Mg}$ & -59.2 & 6.7 & 104.6 & -177.3 & -229.5 & -118.2 \\
\hline $\mathrm{Fe}$ & -20.8 & 25.2 & 144.1 & -7.5 & -43.7 & -124.1 \\
\hline $\mathrm{Sr}$ & $-1,099,908.0$ & $-125,300.0$ & 267.2 & $-289,900.0$ & $-549,900.0$ & $-1,499,900.0$ \\
\hline $\mathrm{Ce}$ & -11.6 & 42.3 & 73.6 & 7.7 & -19.2 & -19.2 \\
\hline $\mathrm{Nd}$ & 31.8 & 54.5 & 68.3 & 59.1 & 42.7 & -27.3 \\
\hline
\end{tabular}

\begin{tabular}{|c|c|c|c|c|c|c|}
\hline \multirow[t]{2}{*}{ Element } & \multicolumn{3}{|l|}{ Alamine 336} & \multicolumn{3}{|c|}{ Aliquat 336} \\
\hline & Kerosene & Xylene & Benzene & Kerosene & Xylene & Benzene \\
\hline $\mathrm{Mg}$ & -131.8 & 9.0 & -229.5 & -86.4 & -150.0 & -140.9 \\
\hline $\mathrm{Fe}$ & -83.9 & 25.2 & -175.9 & -72.4 & -32.2 & -101.1 \\
\hline $\mathrm{Sr}$ & $-2,999,900.0$ & $-180,700.0$ & $-449,900.0$ & ND & $-75,900.0$ & ND \\
\hline $\mathrm{Ce}$ & -61.5 & 34.5 & -50.0 & 11.5 & 15.4 & -15.4 \\
\hline $\mathrm{Nd}$ & -4.5 & 40.9 & -31.8 & 10.0 & 20.5 & -9.1 \\
\hline
\end{tabular}

\begin{tabular}{llllll}
\hline Extracting time & 3 Min & 10 Min & 15 Min & 20 Min & 30 Min \\
Extractants & Aliquat 336 & Aliquat 336 & Alamine 336 & Aliquat 336 & Aliquat 336 \\
Element & Xylene & Xylene & Xylene & Kerosene & Kerosene \\
\hline $\mathrm{Mg}$ & -22.7 & -79.5 & -68.2 & -177.3 & -86.4 \\
$\mathrm{Fe}$ & -14.9 & -66.7 & 1.0 & -7.5 & -72.4 \\
$\mathrm{Sr}$ & -150.0 & -49.0 & 0.0 & $-289,900.0$ & $\mathrm{ND}$ \\
$\mathrm{Ce}$ & 30.4 & 7.7 & 0.0 & 7.7 & 11.5 \\
$\mathrm{Nd}$ & 55.0 & 29.1 & 0.0 & 59.1 & 10.0 \\
\hline
\end{tabular}

and increases the stability of the complex formed in extraction process [18].

\section{Phase 2: Evaluation of uranium extraction using Aliquat 336 in different diluents}

\section{Extraction of uranium with 5\% Aliquat 336 diluted in $95 \%$ kerosene, toluene and xylene}

The extraction of uranium with Aliquat 336 in kerosene, toluene and xylene was investigated. There was no formation of a third phase observed during the extraction of uranium with xylene and toluene, as was the case with kerosene. Due to the formation of the third phase, and inconsistence at 30 and 60 min (Table 7), Kerosene was eliminated from the experiment. These results indicate that the uranyl ion present in ammonium carbonate solution does not complex easily with the extractant when diluted with kerosene. The extractant composition was 5\% Aliquat 336 mixed with xylene to a total of $100 \mathrm{ml}$ in a volumetric flask. A ratio of 1:1 volume of aqueous/organic solution was used for the extraction process and the samples were prepared in triplicates. The same 
Table 7 Results of uranium extracted with 5\% Aliquat 336 and $95 \%$ Kerosene

\begin{tabular}{lll}
\hline $\begin{array}{l}\text { Extraction } \\
\text { time (min) }\end{array}$ & $\mathrm{D}$ & $\% \mathrm{E}$ \\
\hline 0 & 0 & 0 \\
15 & 0.09 & 8.19 \\
30 & 0.01 & 0.54 \\
45 & 0.03 & 2.58 \\
60 & 0.01 & 0.76 \\
\hline
\end{tabular}

procedure was used for Aliquat 336 in toluene. The graph in Fig. 2 shows the extraction percentage of uranium with Aliquat 336 in xylene at various times. For Aliquat 336 in xylene, the extraction percentage was found to be $71 \%$ at $15 \mathrm{~min}$ which deceased at $30 \mathrm{~min}$ and then increased again to $72 \%$ at 60 min. Extraction of uranium using Aliquat 336 in toluene was also investigated. Uranium extraction percentage increases with time from 0 to $30 \mathrm{~min}$ and slightly decreases thereafter. This implies that for toluene the optimum rotation time for the mixture of aqueous and organic solutions is $30 \mathrm{~min}$ (Fig. 3). At $30 \mathrm{~min}$ an extraction percentage of $82 \%$ for uranium in toluene was reached and as time increased from 45 to $60 \mathrm{~min}$, the extraction percentage decreased from 78 to $76 \%$.

The equilibrium time was optimized as $30 \mathrm{~min}$ for uranium extraction in all further experiments, and toluene was chosen as the best diluent due to higher extraction of uranium Fig. 3.

\section{Evaluation of the best concentration of Aliquat 336}

The extraction percentage of uranium using Aliquat 336 concentrations of 5\%,15\%,30\% and 50\% with toluene was investigated. In Fig. 4, it can be seen that the extraction percentage of uranium increases from 80 to $90 \%$ as the concentration of Aliquat 336 increases from 5 to $15 \%$, but decreased at higher Aliquat 336 concentrations. This implies the optimum concentration percentage of Aliquat 336 is $15 \%$.

\section{Conclusion}

The experimental investigation reported here studied extraction of surrogates from alkaline solutions. From Table 6 , it was concluded that the optimum extraction time was 15 min with Alamine 336 in xylene.

The study of uranium extraction from alkaline solutions was also investigated. An amine based extractant Aliquat 336 was proposed as a promising extractant for the uranium extraction without extracting other elements. kerosene, xylene and toluene were proposed diluents for the

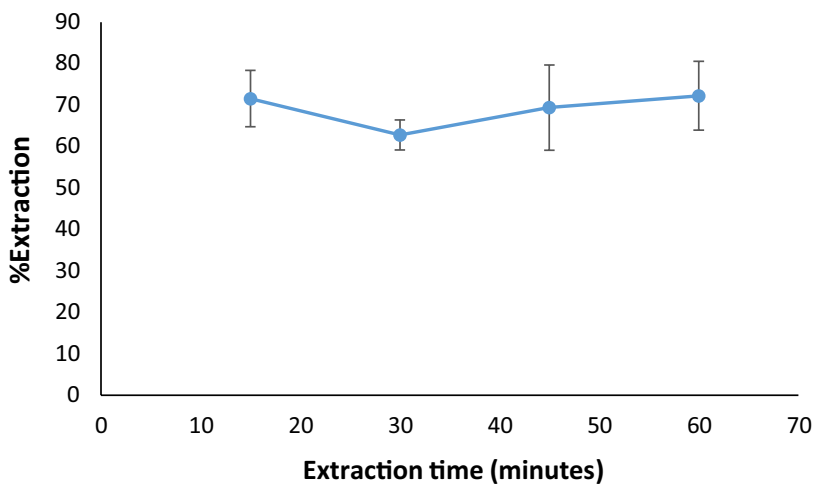

Fig. 2 Extraction percentage of uranium in $1 \mathrm{M}$ ammonium carbonate in 5\% Aliquat 336 in Xylene

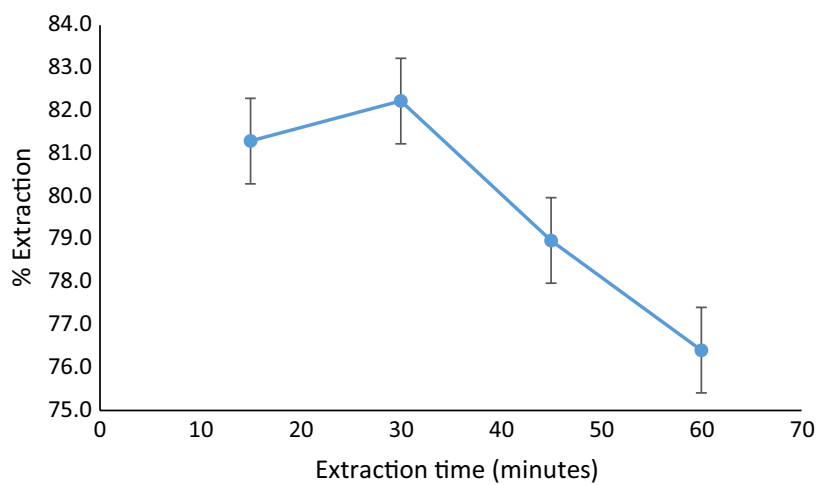

Fig. 3 Extraction percentage of uranium in $1 \mathrm{M}$ ammonium carbonate in 5\% Aliquat 336 in Toluene

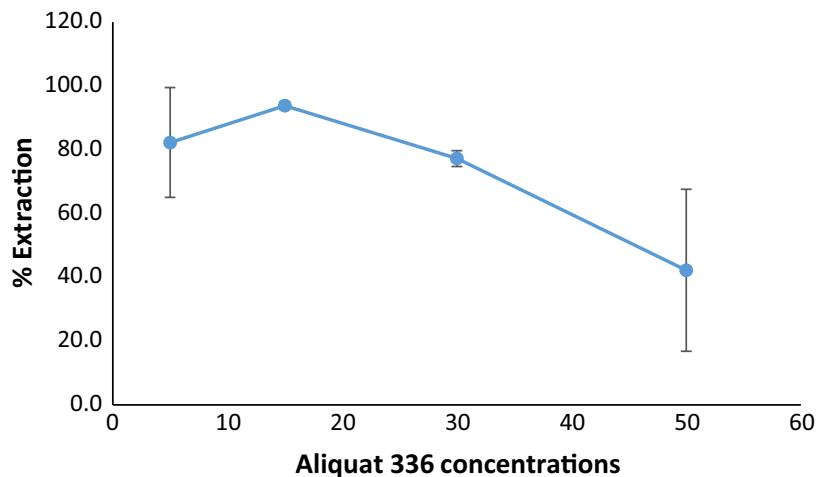

Fig. 4 The effect of Aliquat 336 concentration with constant $0.9 \mathrm{M}$ $\mathrm{H}_{2} \mathrm{O}_{2}, 1 \mathrm{M}\left(\mathrm{NH}_{4}\right)_{2} \mathrm{CO}_{3}$ and $\mathrm{U}$

experiment. In the results above, it is shown that kerosene forms a third phase. Due to this third phase, kerosene was eliminated from the experiment. Toluene was found to be the best diluent with the optimum extraction time of $30 \mathrm{~min}$. Evaluation of different concentrations of Aliquat 336 showed 
that at a concentration of $15 \%$ of Aliquat 336 , the extraction percentage was found to be $93 \%$, therefore it is concluded that $15 \%$ of Aliquat 336 is the optimum concentration.

Acknowledgements The first author would like to acknowledge the National Research Foundation (NRF-SAHARP) for funding this Project. We also acknowledge the guidance given by Prof WH Meyer in this research.

Open Access This article is distributed under the terms of the Creative Commons Attribution 4.0 International License (http://creativeco mmons.org/licenses/by/4.0/), which permits unrestricted use, distribution, and reproduction in any medium, provided you give appropriate credit to the original author(s) and the source, provide a link to the Creative Commons license, and indicate if changes were made.

\section{References}

1. Semião AJC, Rossiter HMA, Schäfer AI (2010) Impact of organic matter and speciation on the behaviour of uranium in submerged ultrafiltration. J Membr Sci 348(1-2):174-180

2. Kulkarni S, Ballal A, Apte SK (2013) Bioprecipitation of uranium from alkaline waste solutions using recombinant Deinococcus radiodurans. J Hazard Mater 262:853-861

3. de Souza AL, Cotrim MEB, Pires MAF (2013) An overview of spectrometric techniques and sample preparation for the determination of impurities in uranium nuclear fuel grade. Microchem $\mathrm{J}$ 106:194-201

4. Kweto B, Groot D, Stassen E, Suthiram J, Zeevaart JR (2014) Kinetic study of uranium residue dissolution in ammonium carbonate media. J Radioanal Nucl Chem 302(1):131-137

5. Stassen L, Suthiram J (2015) Initial development of an alkaline process for recovery of uranium from 99Mo production process waste residue. J Radioanal Nucl Chem 305(1):41-50

6. Quinn JE, Wilkins D, Soldenhoff KH (2013) Solvent extraction of uranium from saline leach liquors using DEHPA/Alamine 336 mixed reagent. Hydrometallurgy 134:74-79

7. Smith SC, Peper SM, Douglas M, Ziegelgruber KL, Finn EC (2009) Dissolution of uranium oxides under alkaline oxidizing conditions. J Radioanal Nucl Chem 282(2):617-621
8. Kim C-J, Kumar JR, Kim J-S, Lee J-Y, Yoon H-S (2012) Solvent extraction studies on uranium using amine based extractants and recovery from low grade ore leach liquors. J Braz Chem Soc 23:1254-1264

9. Zhu Z, Pranolo Y, Cheng CY (2013) Uranium solvent extraction and separation from vanadium in alkaline solutions. Sep Sci Technol 48(9):1402-1408

10. Stepanov S et al (2011) CARBEX process, a new technology of reprocessing of spent nuclear fuel. Russ J Gen Chem 81(9):1949-1959

11. Fourie M, Meyer WCMH, van der Westhuizen DJ, Krieg HM (2016) Uranium recovery from simulated molybdenum-99 production residue using non-dispersive membrane based solvent extraction. Hydrometallurgy 164:330-333

12. Sameh AA (1984) Nuclear fuel decontamination in basic solutions. Proc Am Nucl Soc Int Top Meet Fuel Reprocess Waste Manag 1:227-237

13. Edwards C, Oliver A (2000) Uranium processing: a review of current methods and technology. JOM 52(9):12-20

14. Peper SM, Brodnax LF, Field SE, Zehnder RA, Valdez SN, Runde WH (2004) Kinetic study of the oxidative dissolution of $\mathrm{UO}_{2}$ in aqueous carbonate media. Ind Eng Chem Res 43(26):8188-8193

15. Asanuma N, Harada M, Ikeda Y, Tomiyasu H (2001) New approach to the nuclear fuel reprocessing in non-acidic aqueous solutions. J Nucl Sci Technol 38(10):866-871

16. Asanuma $\mathrm{N}$ et al (2006) Anodic dissolution of $\mathrm{UO}_{2}$ pellet containing simulated fission products in ammonium carbonate solution. J Nucl Sci Technol 43(3):255-262

17. Kweto B (2013) Recovery of uranium from uranium residue by alkaline leaching. University of Pretoria, Pretoria

18. Nasab ME (2014) Solvent extraction separation of uranium(VI) and thorium(IV) with neutral organophosphorus and amine ligands. Fuel 116:595-600

Publisher's Note Springer Nature remains neutral with regard to jurisdictional claims in published maps and institutional affiliations. 